ISSN : 2581-1320 (Print) ISSN : 2581-2572 (Online)

Homepage: http://ejurnal.ikippgribojonegoro.ac.id/index.php/J-ABDIPAMAS

\title{
PROGRAM HOME INDUSTRI PRODUKSI JILBAB SYAR'I BAGI PKK KAMPUNG BUNSUR UNTUK MENINGKATKAN PEREKONOMIAN MASYARAKAT DESA BUNSUR KECAMATAN SUNGAI APIT KABUPATEN SIAK
}

\author{
Feranita $^{1}$, Ery Safrianti ${ }^{2}$, Nurhalim ${ }^{3}$, Dian Yayan Sukma ${ }^{4}$, Yusnita Rahayu $^{5}$, Salhazan 6 , \\ Linna Oktaviana Sari ${ }^{7}$
}

\author{
${ }^{1}$ Universitas Riau.Email: feranita@lecturer.unri.ac.id \\ 2Universitas Riau. Email: esafrianti@eng.unri.ac.id \\ 3Universitas Riau. Email: nurhalim@lecturer.unri.ac.id \\ 4Universitas Riau. Email:dianyayan.sukma@eng.unri.ac.id \\ 5Universitas Riau. Email: yusnita.rahayu@lecturer.unri.ac.id \\ 6Universitas Riau. Email: salhazan@lecturer.unri.ac.id \\ 7Universitas Riau. Email: linnaoasari@lecturer.unri.ac.id
}

\begin{abstract}
The hijab sewing skills training program is seen as a strategic educational skill to be implemented for women because hijab sewing can be applied for their own needs or become a side business. This skill, if properly trained and mastered, can become a form of business that can help the family economy and create jobs for the community. The village community service activities were carried out in Bunsur Village, Sungai Apit Subdistrict, Siak Regency, Riau Province with the target audience is the housewives of the village. They have given basic knowledge in choosing materials for the hijab. Then skills trained was held, starting how to make pet and headscarves, cutting fabrics according to the patterns that have been made, and sewing headscarves with various existing patterns. After the stitches are finished, then an examination of the results of the stitches so that they are suitable for sale and market.
\end{abstract}

Keywords: Bunsur Village, home industry, sewing training, hijab

\begin{abstract}
ABSTRAK
Program pelatihan keterampilan menjahit jilbab dipandang sebagai sebuah skill pendidikan yang strategis untuk dilaksanakan bagi wanita karena menjahit jilbab dapat diaplikasikan untuk kebutuhan sendiri ataupun menjadi usaha sampingan. Keterampilan ini bila dilatih dan dikuasai dengan baik dapat menjadi bentuk usaha yang dapat membantu perekonomian keluarga dan penciptaan lapangan kerja bagi masyarakat. Kegiatan pengabdian kepada masyarakat desa ini dilaksanakan di Desa Bunsur Kecamatan Sungai Apit Kabupaten Siak Propinsi Riau dengan khalayak sasarannya adalah Ibu-ibu rumah tangga desa tersebut. Mereka diberi pengetahuan dasar dalam memilih bahan untuk jilbab. Kemudian diadakan pelatihan keterampilan, mulai cara membuat pola pet dan jilbab, memotong kain sesuai dengan pola yang sudah dibuat, dan menjahit jilbab dengan bermacam pola yang telah ada. Setelah jahitan selesai, kemudian dilakukan pemeriksaan terhadap hasil jahitan sehingga layak untuk dijual dan dipasarkan.
\end{abstract}

Kata Kunci: Desa Bunsur, home industri, pelatihan menjahit, jilbab 


\section{PENDAHULUAN}

Desa Bunsur merupakan salah satu desa yang berada di wilayah Kecamatan Sungai Apit, kabupaten Siak. Desa ini terletak $65 \mathrm{~km}$ ke arah timur dari ibu kota kecamatan. Desa Bunsur mempunyai luas wilayah seluas 9000 hektar. Jumlah desa yang ada di Kecamatan Sungai Apit sebanyak 13 desa.

Desa Bunsur sebagaimana desa-desa di wilayah Indonesia beriklim tropis ( musim hujan dan musim panas ). Hal ini sangat mempengaruhi terhadap pola mata pencaharian masyarakat Desa Bunsur yang bukan hanya berkebun saja, tetapi juga melaut di Selat Lalang, yang berhulu di Selat Malaka. Jumlah penduduk di Desa Bunsur ini adalah 1.109 Jiwa,121 kepala keluarga. Desa yang dibentuk pada tahun 2002 ini terbagi atas 2 dusun, 8 rukun tetangga, dan 4 rukun warga. Adapun tingkat pendidikan mayoritas masyarakat di Desa Bunsur memiliki tingkat pendidikan yang rendah. (Nurhalim, dkk, 2016)

Salah satu pemasalahan yang dialami mayarakat di Desa Bunsur adalah di sektor perekonomian, dimana penghasilan dari masyarakat desa tergantung pada hasil pertanian dan hasil tangkapan ikan yang tidak menentu. Salah satu solusi terhadap permasalahan ini merupakan tujan dari kegiatan pengabdian masyarakat yaitu meningkatkan perekonomian masyarakat petani dan nelayan di desa Bunsur Kecamatan Sungai Apit Kabupaten Siak melalui program home industri yang menghasilkan barang jadi berupa jilbab dengan beragam model. Program dilakukan dengan memberikan keterampilan dasar menjahit jilbab, memberikan ketrerampilan dalam membuat bermacam pola jilbab, memberikan keterampilan dalam menentukan apakah hasil dari jahitan sudah dapat dipasarkan, dan memonitoring hasil dari program home industry dan melakukan pembinaan secara berkesinambungan terhadap permasalahan yang mungkin timbul dalam proses menciptakan home industri dengan produksi yang stabil.

Khalayak sasaran kegiatan ini adalah ibu-ibu PKK di desa Bunsur Kecamatan Sungai Apit Kabupaten Siak. Melalui kegiatan pengabdian ini dapat terbentuknya sebuah peluang usaha dalam bentuk home industri, sehingga perekonomian masyarakat dapat ditingkatkan.

Membentuk keluarga sejahtera pada dasarnya adalah menggerakkan proses dan fungsi manajemen dalam kehidupan rumah tangga, sehingga seorang ibu dituntut untuk kreatif, sabar, ulet dan tekun dalam mencapai kesejahteraan keluarga. Banyak hal yang bisa dilakukan seorang ibu dalam menopang ekonomi keluarga yaitu dengan cara berwirausaha, bekerja di perusahaan swasta maupun pemerintah, bahkan menjadi kuli kasar ataupun mengerjakan pekerjaan lainnya yang biasa dilakukan oleh laki-laki. Dari pernyataan diatas, terlihat bahwa seorang Ibu memiliki peran ganda yaitu disamping tugas pokoknya sebagai pengurus rumah tangga, seorang ibu bisa juga membantu perekonomian keluarga yang tentunya harus dengan izin suaminya agar tidak menimbulkan konflik dalam rumah tangga. Dengan demikian, seorang ibu sangat berperan dalam pemberdayaan ekonomi keluarga guna mencapai kesejahteraan keluarga (Harjawati, dkk, 2018) 
Mesin jahit merupakan salah satu perangkat yang sangat dibutuhkan dalam pembuatan busana (pakaian). Dengan mesin jahit pembuatan pakaian mudah, semakin cepat dan pakaian terlihat lebih rapi dan indah. Penggunaan mesin jahit dalam pembuatan busana telah dimulai ratusan tahun silam. Para perancang busana telah berabad-abad lamanya banyak dibantu untuk mewujudkan cipta karyanya melalui mesin pembuatan busana/pakaian ini. Mesin jahit mempunyai fungsi menyatukan potongan-potongan kain yang telah dipola, yaitu diukur, dibentuk dan dipotong sesuai bentuk tubuh manusia untuk disatukan, disambungkan supaya membentuk menjadi sebuah pakaian yangnyaman dipakai, indah dipandang dan menciptakan kepribadian bagi pemakainya. Pada awal penemuannya, selain bentuk yang sederhana dan dioperasikan secaramanual, mesin jahit hanya berfungsi membuat jahitan (setikan) lurus saja. Dengankemajuan teknologi disegala bidang, teknologi mesin jahit tidak saja dijalankan dengan tenaga listrik, tetapi mempunyai kemampuan yang beraneka macam,sesuai dengan tipe dan karakteristik masing-masing. Mesin jahit yang berkembang dewasa ini mempunyai kecepatan menjahit yang sangat tinggi (highspeed), mesin-mesin yang mmempunyai setikan rapi, untuk itu yang sangatpenting dan harus diperhatikan adalah penguasaan bagian-bagiannya dan caramengoperasikannya, bagimana mesin-mesin ini sangat membantu industri pakaian dapat mewujudkan karyakarya desain. (Prihati, 2013).

Jenis-jenis pola pet jilbab dapat dijelaskan sebagai berikut.

a. Pet biasa

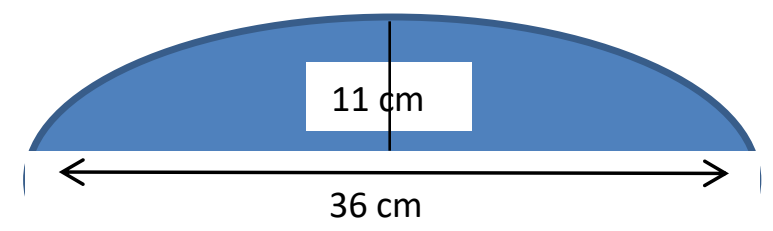

Gambar 1. Pola pet biasa

b. Pet antem

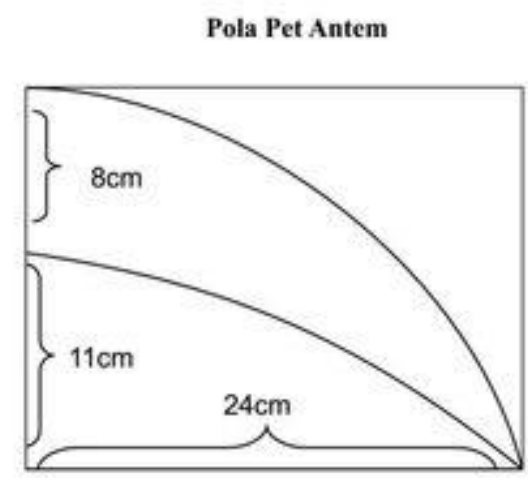

Gambar 2. Pola pet antem 
Sedangkan Jenis-jenis pola jilbab dapat dijelaskan sebagai berikut.

a. Pola jilbab khimar

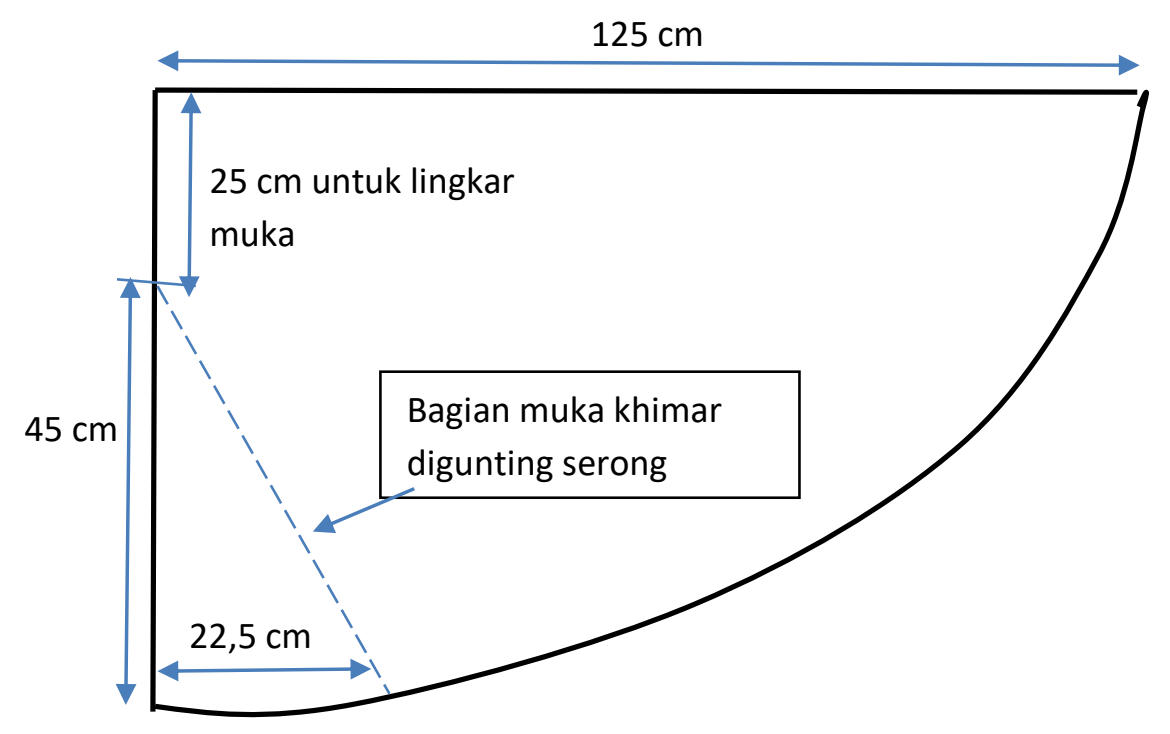

Gambar 3. Pola jilbab khimar

b. Pola jilbab pinguin

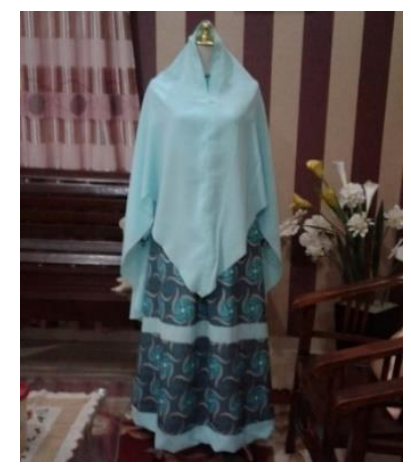

Gambar 4. Pola jilbab pinguin

Macam-macam model jilbab Layer dapat dijelaskan pada gambar berikut.

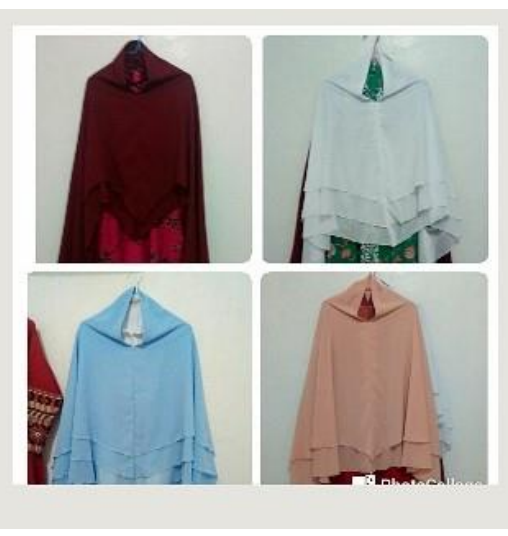

Gambar 5. Model jilbab layer 1

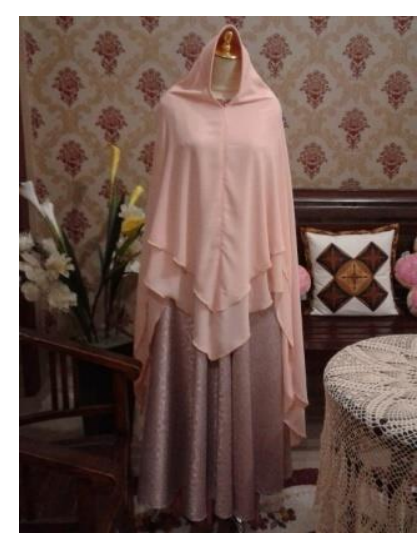

Gambar 6. Model jilbab layer 2

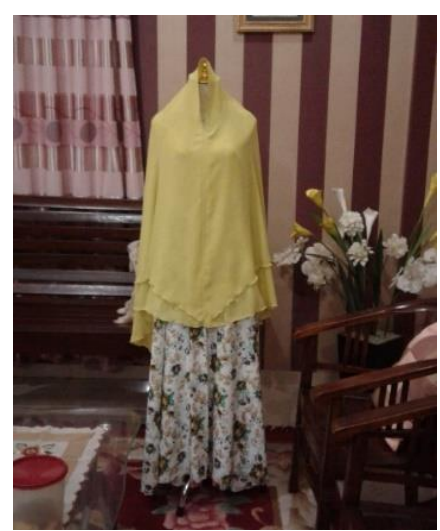

Gambar 7. Model jilbab layer 3 


\section{METODE PELAKSANAAN}

Metode penerapan pelaksanaan kegiatanpengabdian dirancang beberapa tahapan sebagai berikut:

\section{Survei Lokasi}

Survei dilakukan untuk mengidentifikasi lokasi tempat kegiatan agar diperoleh data-data awal khalayak sasaran. Survei ini mencakup data geografis, penduduk, pendidikan dan ekonomi. Pada tahapan ini, tim juga berdiskusi dengan kepala desa setempat tentang persoalan yang ada di desa Bunsur ini.

\section{Persiapan}

Ada beberapa langkah persiapan tim dalam melaksanakan kegiatan yakni koordinasi dengan pihak terkait di lokasi, koordinasi sesama tim, mempersiapkan model tempat pengeringan dan pengujian data lapangan. Kemudian, tim mempersiapkan beberapa alat dan bahan yang dibutuhkan.

\section{Pelaksanaan Kegiatan}

Kegiatan direncanakan selama dua tahun, tahun ke-1 akan menyiapkan 2 sentra home industri, yaitu pertama untuk perancangan dan pengembangan model jilbab dan sentra yang kedua, untuk memproduksi jilbab sampai siap untuk dipasarkan. Pada tahun ke-2 menyiapkan 1 sentra untuk pemasaran dan promosi hasil home industri sambil terus memonitoring, membina dan mengembangkan sentra perancangan dan sentra produksi.. Target tahun pertama, sentra perancangan dapat menguasai model jilbab untuk anak dan dewsa minimal 5 pola. Sentra produksi dapat menghasilkan semua model dari pola jilbab pada sentra perancangan melalui keterampilan menjahit, mengobras dan mensirsak. Target tahun kedua, dapat mengemas hasil produksi yang siap untuk dipasarkan serta melakukan promosi secara langsung maupun melalui pemasaran online.

\section{Laporan Kegiatan}

Tim mempersiapkan laporan kegiatan sebagai bentuk pertanggung jawaban terhadap Lembaga Penelitian dan Pengabdian kepada Masyarakat Universitas Riau. Laporan ini memuat cakupan materi kegiatan dan dokumentasi

\section{HASIL DAN PEMBAHASAN}

Dalam pelaksanaan yang telah dilakukan, pada bagian awal kegiatan memberikan pelatihan membuat bermacam-macam pola pet pada kertas (pet busa, pet antem dan tanpa pet), memotong pola tersebut pada kain dan menjahitnya. Selanjutnya pelatihan membuat 5 macam pola jilbab, yaitu jilbab model standart, model pinguin, jilban 1 layer, jilbab 2 layer dan jilbab 3 layer. Dalam pelatihan ini diajarkan bagaiman membuat pola pada kertas, memotong pola tersebut pada kain dan menjahitnya. Selanjutnya juga diajarkan cara menjahit pinggir jilbab (klem). 


\section{Pelatihan Membuat Pola Pet}

Macam-macam isian pet :

1. Busa dan spon ati

2. Visilin atau pelapis tipis atau kain kapas digunting sesuai pola jahit.

3. Kain keras biasanya untuk kerah atau ban pinggang, dipotong lebih kecil $1 \mathrm{~cm}$ dari pola kain

4. Kain pasir atau morigula, biasanya digunakan dua morigula dan dipotong sesuai lebar pet.

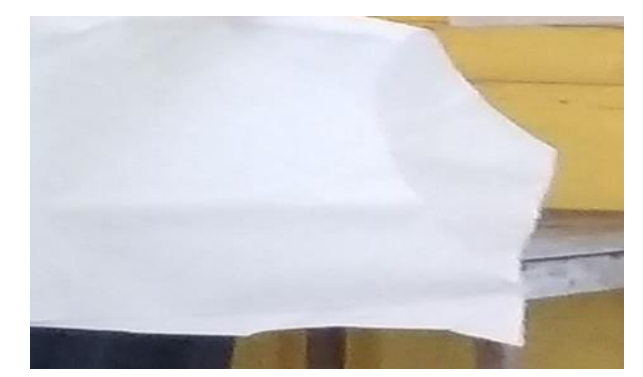

Gambar 8. Kain keras untuk isian pet jilbab

Cara membuat pet antem :

1. Pola pet yang digunakan adalah kain keras dan untuk isiannya dapat digunakan viseilin.

2. Letakkan pola pet diatas kain yang sudah terlipat berdasarkan serat memanjangnya

3. Gunting kain dengan melebihkannya sepanjang $1 \mathrm{~cm}$

4. Setrika sisi isian dan sisi lapisan kain keras pet

5. Pertemukan kedua sisi pet tersebut, yaitu kain dengan kain.

6. Kemudian jahit untuk menyambungkan kedua pet tersebut sesuai dengan bentuk lengkungan pet pada bagian bawah

7. Setelah terjahit, maka gunting pada jahitan tersebut dan sisakan $0,5 \mathrm{~cm}$ untuk memperkecil lipatan.

8. Kampuhnya kita cacah atau gunting kecil-kecil sekeliling cekungan yang fungsinya adalah pada saat kita balik pet tersebut menjadi rapi.

9. Buat tindasan atau jahitan lebarnya kurang lebih $2 \mathrm{~mm}$ pada bagian viselin karena bagian viselin ini akan diletakkan pada bagian dalam petnya.

10. Buat jahitan sejalur

Cara membuat pola pet antem untuk pet antem sampai pipi :

1. Ambil kertas untuk pola dan lipat menjadi dua bagian

2. Ukur sejauh $8 \mathrm{~cm}$ (bisa 5 atau $11 \mathrm{~cm}$, semakin besar angkanya maka petnya akan semakin rendah) untuk membuat lengkungan pet

3. Ukur sejauh $7 \mathrm{~cm}$ untuk lebar pet ( bisa 5 ata $9 \mathrm{~cm}$ )

4. Panjang pet diukur dari sudut kertas sejauh $18 \mathrm{~cm}$ ( bisa $19 \mathrm{~cm}$ )

5. Hubungkan titik lebar pet bagian atas ke arah panjang pet dan bagian bawah ke arah panjang pet

6. Kemudian gunting pola tersebut. 
Cara membuat pola pet antem untuk pet antem sampai dagu :

1. Ambil kertas untuk pola dan lipat menjadi dua bagian

2. Ukur sejauh $8 \mathrm{~cm}$ (bisa 5 atau $11 \mathrm{~cm}$, semakin besar angkanya maka petnya akan semakin rendah) untuk membuat lengkungan pet

3. Ukur sejauh $7 \mathrm{~cm}$ untuk lebar pet ( bisa 5 ata $9 \mathrm{~cm}$ )

4. Panjang pet diukur dari sudut kertas sejauh $23 \mathrm{~cm}$ ( bisa $22-25 \mathrm{~cm}$ )

5. Hubungkan titik lebar pet bagian atas ke arah panjang pet dan bagian bawah ke arah panjang pet

6. Kemudian gunting pola tersebut

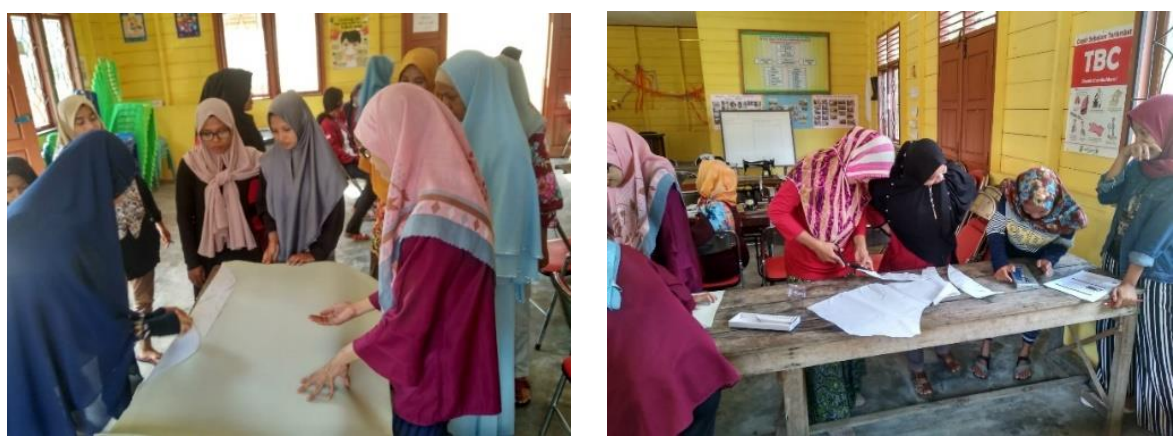

Gambar 9. Memperbanyak pola pet yang telah dibuat untuk pelatihan

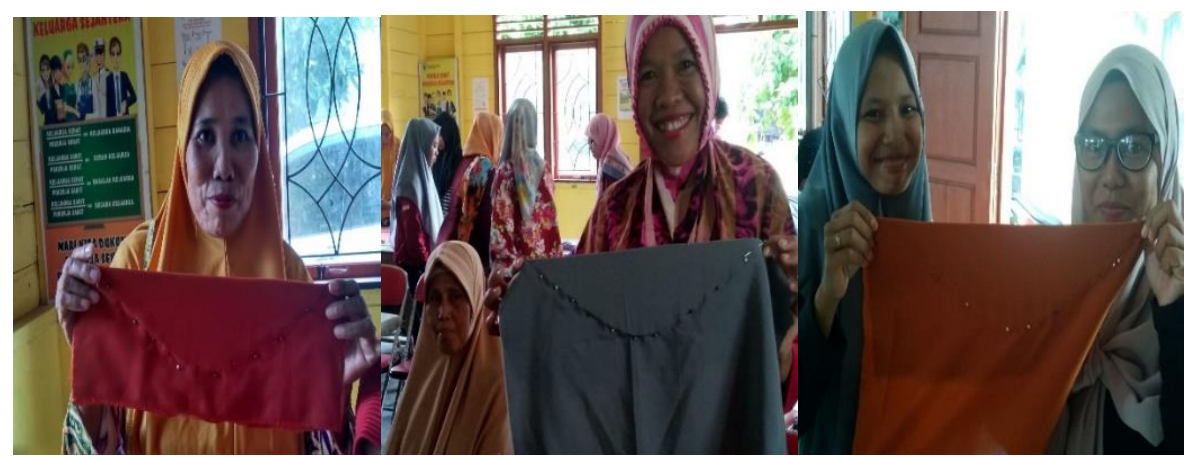

Gambar 10. Pet Busa yang siap untuk dijahit alur
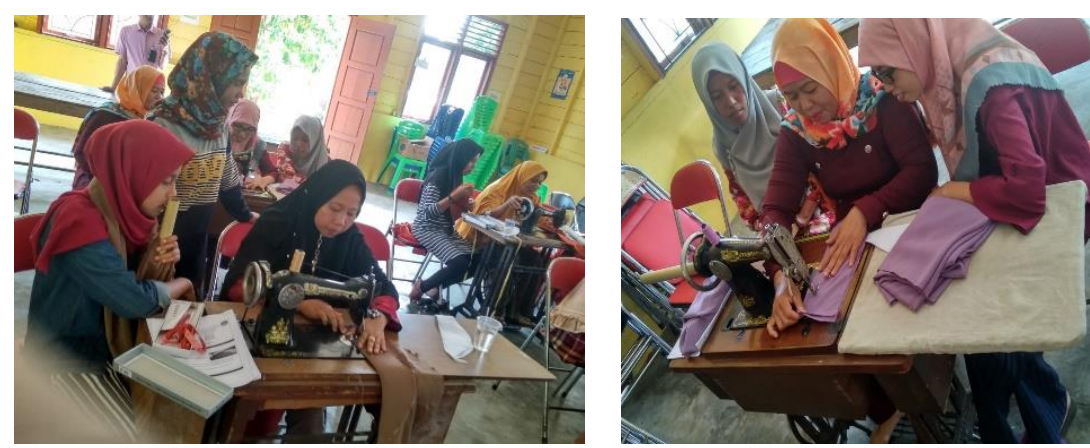

Gambar 11. Proses pembuatan alur pada pet jilbab 


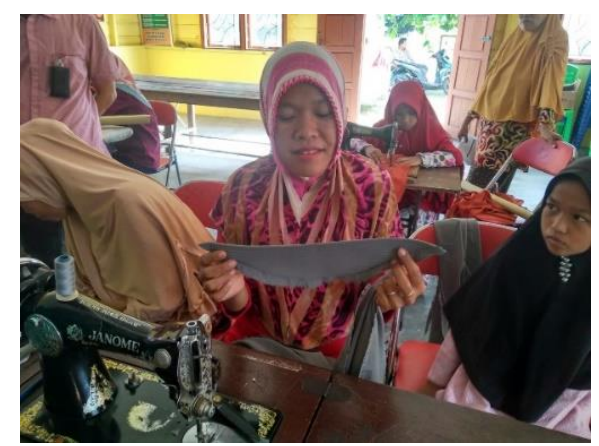

Gambar 12. Pet jilbab yang sudah dibuat alur

\section{Pelatihan Membuat Pola Jilbab pada kain}

Cara membuat khimar untuk pet antem langsung pada kain :

1. Siapkan kain lebar $150 \mathrm{~cm}$,bidang 150 dan lipat dua

2. Ukur panjang depan khimar sepanjang $76 \mathrm{Cm}$ dari ujung lipatan lalu tandai

3. Ukur panjang belakang khimar sepanjang $120 \mathrm{~cm}$ dari ujung ke arah serat lebar kain dan tandai

4. Bentuk lengkung khimar dimulai dari arah titik pertemuan tadi ke arah depan dan begitu juga ke arah belakang khimar. Boleh lengkung atau segitiga

5. Untuk membentuk garis tengah khimar yang nanti jatuhnya kurang lebih di lengan khimar sejauh $40 \mathrm{~cm}$ dari depan khimar dan Ukur dari lipatan atas khimar sejauh 45 $\mathrm{cm}$ dan beri tanda pada titik pertemuan tersebut

6. Untuk membentuk lubang khimar, ukur $5 \mathrm{~cm}$ pada bagaian lipatan dan $26-30 \mathrm{~cm}$ bagian bawah tergantung lingkat kepala dan sambungkan kedua titik dengan membuat lengkungan untuk muka. Sudut pada bagian bawah dipapras supaya gampang menjahitnya.

7. Gunting pola khimar sesuai dengan gais pola yang telah dibuat.

8. Untuk bagian depan gunting sejauh $1 \mathrm{~cm}$ supaya jahitan dengah mukanya rapi dan tidak berkerut.

9. Untuk layer kedua menggunakan sisa kain dan lipat menjadi dua.

10. Letakkan khimar yang telah dipotong tadi diatas kain yang sudah dilipat sebagai pola dan lebihkan sejauh $8 \mathrm{~cm}$ sampai $10 \mathrm{~cm}$ dari pola khimar Pertama dari beri garis untuk menandai.

11. Gunting pola kedua khimar sesuai dengan garis tersebut 

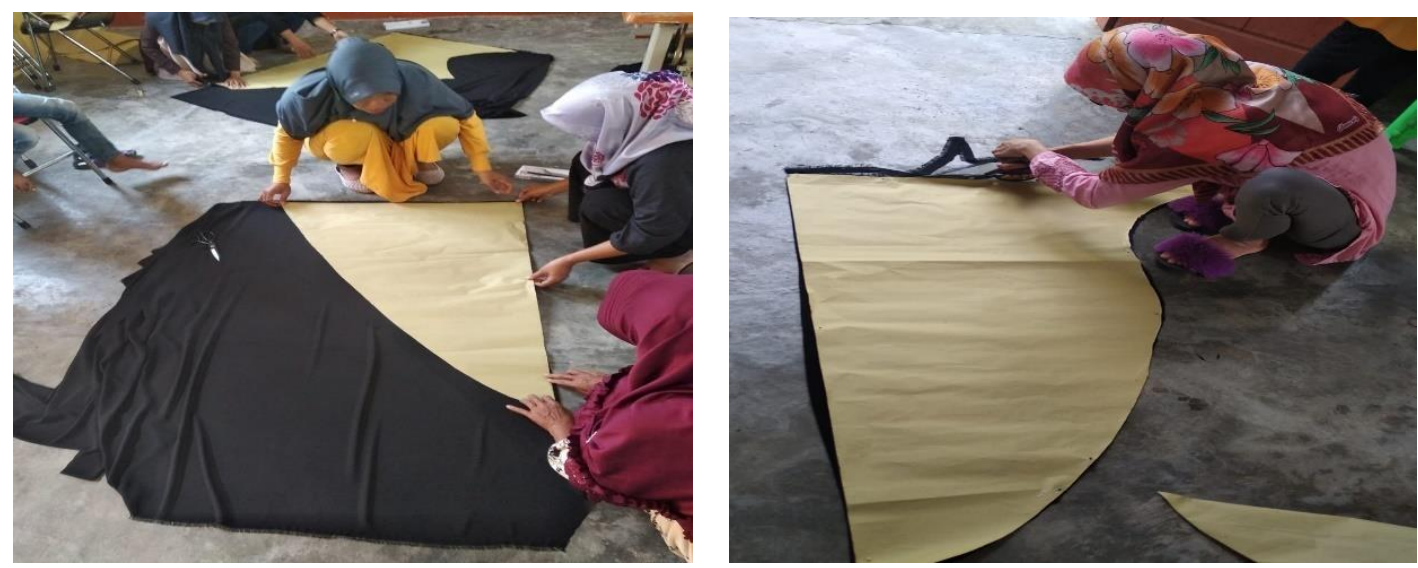

Gambar 13. Memotong kain jilbab sesuai pola yang telah dibuat

\section{Pelatihan Menjahit Jilbab}

Cara Membuat Jilbab :

1. Ambil kain yang lebarnya $1,5 \mathrm{~m}$ dan panjang $2,5 \mathrm{~m}$, kemudian lipat dua kain tersebutmenjadi dua bagian yang sama panjangnya seperti pada gambar 1 dan 2

2. Potong kain secara melengkung seperti pada gambar 3 sehingga diperoleh bentuk jilbab seperti pada gambar 4 .

3. Jahit bagian tepi seperti pada gambar 5 dengan menyisakan bagian atas untuk wajah (yaitu ukuran lingkar wajah dibagi dua.

4. Untuk membuat pet jilbab, gunakan sisa potongan kain

5. Letakkan busa jilbab yang sudah dipotong pada sisa potongan kain tersebut

6. Lipat dua sisa kain tersebut sehingga busa jilbab tertutup dan beri pentul untuk pentul merapikannya

7. Jahit busa jilbab searah panjang busa sejarak $1 \mathrm{~cm}$ atau seukuran tapak jahitan pada mesin jahit

8. Hubungkan pet jilbab dengan lingkar muka jilbab menggunakan pentul dan jahit lingkat muka bersamaan dengan pet.

9. Obras bagian lingkar muka

10. Bagian bawah jilbab dineci atau jika diberi renda, maka cukup diobras saja.

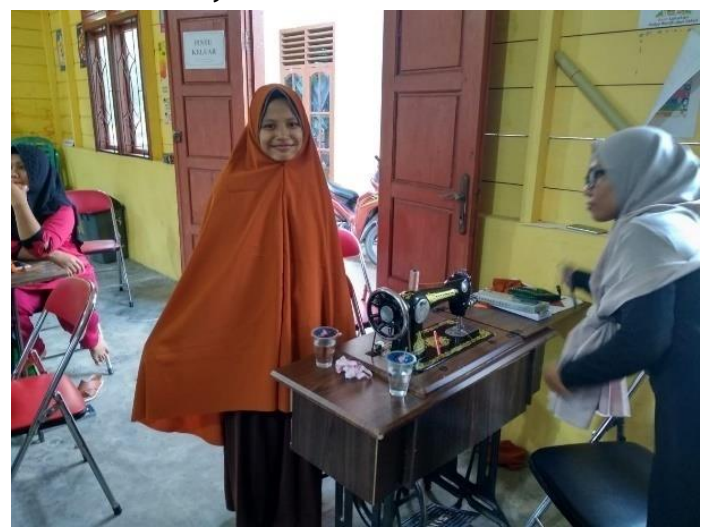

Gambar 14. Hasil jahitan yang sudah tersambung antara pet dan khimar 


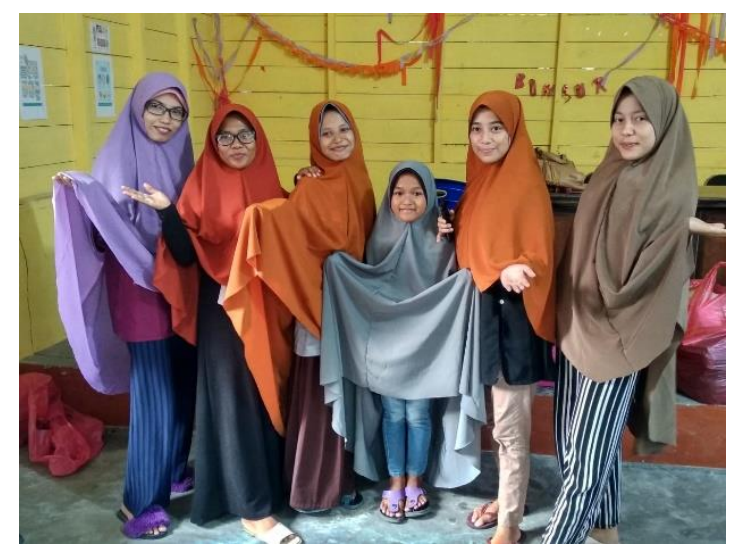

Gambar 15. Salah satu model jilbab yang dihasilkan oleh ibu-ibu PKK Desa Bunsur pada saat pelatihan

Pada akhir pelatihan, para peserta dibekali satu paket bahan jilbab dan diberi tugas untuk menyelesaikan sebuah jilbab dengan menggunakan pola yang telah diberikan. Hasil dari tugas ini harus digunakan pada saat penutupan kegiatan pengabdian yang akan dilaksanakan pada tanggal 20 Oktober 2019.

Sesuai dengan tujuan yang akan dicapai dari kegiatan pengabdian bina desa di tahun pertama ini, yaitu peserta mendapatkan keterampilan dasar membuat pola dan menjahit jilbab, maka dari hasil monitoring yang telah dilakukan, pelatihan yang dilakukan telah berhasil. Hal ini berdasarkan informasi yang diperoleh dari salah satu anggota peserta, bahwa yang bersangkutan sudah membeli satu perangkat mesin jahit portable karena suudah ada permintaan atau pesanan jilbab dari warga.

Pengabdian home industri membuat jilbab syar'i ini mendapat perhatian yang khusus dari pihak desa, dengan akan dibentuknya sebuah unit usaha milik desa. Pada bulan januari 2020, pihak desa meminta salah satu dari anggota pelatihan sekaligus ketua kelompok peserta pelatihan yang bernama ibu Citra untuk membuat Rencana Anggaran Belanja (RAB) untuk diajukan ke pihak desa untuk pembentukan unit usaha di desa Bunsur.

\section{SIMPULAN}

Kegiatan pengabdian masyarakat di Desa Bunsur berupa pelatihan keterampilan menjahit jilbab dengan tujuan terbentuknya home industri telah berjalan dengan baik.Para peserta bersemangat dan antusias mengikuti semua materi dan praktek yang diberikan. Hasil jahitan akan terus di monitoring agar sesuai standar produk untuk dipasarkan.

\section{UCAPAN TERIMA KASIH}

Ucapan terima kasih disampaikankepada Lembaga Penelitian dan Pengabdian Masyarakat (LPPM) Universitas Riau yang memberihibahpengabdianmasyarakatBina Desa dana DIPA tahun anggaran 2019.

\section{DAFTAR RUJUKAN}

Nurhalim, dkk. (2016). Laporan Pengabdian Kepada Masyarakat di desa Bunsur Kecamapatan Sungai Apit Kabupaten Siak. Riau, Indonesia: LPPM Universitas Riau. 
Prihati, S. (2013). Dasar Teknologi Menjahit 1. Direktorat Pembinaan SMK.

Harjawati, T., dkk. (2018). Pemberdayaan ibu-ibu rumah tangga melalui modifikasi Jilbab anak untuk meningkatkan Ekonomi Keluarga di Desa Rocek. Sembadha, 1(1). 
30 J-Abdipamas, Vol. 4, No. 1 April, 2020 